\title{
Patterns of Sociodemographic and Clinicopathologic Characteristics of Stages II and III Colorectal Cancer Patients by Age: Examining Potential Mechanisms of Young-Onset Disease
}

\author{
Caitlin C. Murphy, ${ }^{1,2}$ Hanna K. Sanoff, ${ }^{3}$ Karyn B. Stitzenberg, ${ }^{3}$ John A. Baron,,4 \\ Jennifer L. Lund, ${ }^{2}$ and Robert S. Sandler ${ }^{2,4}$ \\ ${ }^{1}$ Division of Epidemiology, Department of Clinical Sciences, University of Texas Southwestern Medical Center, Dallas, TX, USA \\ ${ }^{2}$ Department of Epidemiology, The University of North Carolina at Chapel Hill, Chapel Hill, NC, USA \\ ${ }^{3}$ Lineberger Comprehensive Cancer Center, The University of North Carolina at Chapel Hill, Chapel Hill, NC, USA \\ ${ }^{4}$ Center for Gastrointestinal Biology and Disease, The University of North Carolina at Chapel Hill, Chapel Hill, NC, USA
}

Correspondence should be addressed to Caitlin C. Murphy; caitlin.murphy@utsouthwestern.edu

Received 26 August 2016; Revised 16 December 2016; Accepted 28 December 2016; Published 23 January 2017

Academic Editor: Lance A. Liotta

Copyright (C) 2017 Caitlin C. Murphy et al. This is an open access article distributed under the Creative Commons Attribution License, which permits unrestricted use, distribution, and reproduction in any medium, provided the original work is properly cited.

\begin{abstract}
Background and Aims. As a first step toward understanding the increasing incidence of colorectal cancer (CRC) in younger (age $<50)$ populations, we examined demographic, clinicopathologic, and socioeconomic characteristics and treatment receipt in a population-based sample of patients newly diagnosed with stages II and III CRC. Methods. Patients were sampled from the National Cancer Institute's Patterns of Care studies in 1990/91, 1995, 2000, 2005, and $2010(n=6,862)$. Tumor characteristics and treatment data were obtained through medical record review and physician verification. We compared sociodemographic and clinicopathologic characteristics and treatment patterns of younger (age $<50$ ) and older (age 50-69, age $\geq 70$ ) CRC patients. Results. Younger patients were more likely to be black (13\%) and Hispanic (15\%) than patients aged 50-69 years (11\% and $10 \%$, resp.) and $\geq 70$ years (7\% each). A larger proportion of young white (41\%) and Hispanic (33\%) patients had rectal tumors, whereas tumors in the right colon were the most common in young black patients (39\%). The majority of younger patients received chemotherapy and radiation therapy, although receipt of microsatellite instability testing was suboptimal (27\%). Conclusion. Characteristics of patients diagnosed with young-onset CRC differ considerably by race/ethnicity, with a higher proportion of black and Hispanic patients diagnosed at the age of $<50$ years.
\end{abstract}

\section{Introduction}

Incidence of colorectal cancer (CRC) in younger adults (age $<50$ years) is rising in the US [1-3]. Despite an aging population, by 2030 , approximately $11 \%$ of colon and $23 \%$ of rectal cancers are expected to be diagnosed in patients below the age of 50 [3]. Underlying mechanisms contributing to this increase are poorly understood, and reasons for the increase in CRC incidence in younger populations remain largely unknown.

Understanding differences in sociodemographic and clinicopathologic characteristics of CRC patients by age may provide an important insight into mechanisms that have contributed to increasing incidence of CRC in younger populations. However, most research in this area is limited to single institution settings or clinic-based samples. Findings from these studies generally reflect characteristics of patients treated at that institution. For example, a number of studies [4-6] show that proximal colon cancers are more common in younger patients, while others report a higher proportion of distal colon or rectal cancers [7-10] in this age groupor even no difference in anatomic subsite by age [11-16]. Relying on results from clinic-based samples may lead to inappropriate conclusions regarding the relative importance of sociodemographic and clinicopathologic characteristics in the development of young-onset CRC because there are 
differences in patient demographics (e.g., race/ethnicity, age) across institutions. As a consequence, we lack an understanding of the characteristics of and factors contributing to youngonset CRC in diverse settings and populations.

To address this gap in the literature, we examined demographic, socioeconomic, and clinicopathologic characteristics of younger and older CRC patients in a population-based sample of stages II and III CRC. We limited the study to stages II and III patients because we expected more variation in treatment with chemotherapy and radiation therapy. As a secondary aim, we also examined the receipt of treatment by age.

\section{Methods}

2.1. Study Population. The study population was derived from the National Cancer Institute's (NCI) Patterns of Care (POC) studies. The NCI annually conducts POC studies on a random sample of patients with select cancers (e.g., breast [1719], colorectal [20-23], and cervical [24]) to complement data routinely collected through the Surveillance, Epidemiology, and End Results (SEER) program of cancer registries. Because chemotherapy administered in outpatient settings is often underascertained by SEER registries (i.e., SEER is primarily hospital-based), POC studies provide important information on the extent to which adjuvant therapies are delivered in community settings. Stages II and III CRC patients in participating SEER registries were included in POC studies in 1990, 1991, 1995, 2000, 2005, and 2010 [21]. Patients were stratified by registry, sex, age, and race/ethnicity, and a random sample was taken from within each stratum. There was oversampling by race/ethnicity in 1995, 2000, 2005, and 2010 to obtain more stable estimates. Patients were ineligible for POC studies if they were below the age of 20 , previously diagnosed with cancer (excluding nonmelanoma skin cancer), diagnosed at autopsy or on death certificate only, or diagnosed with a synchronous cancer. For purposes of this analysis, we further excluded patients with tumors in the appendix $(n=4)$, who did not undergo cancer-directed surgery $(n=171)$, or with incomplete information to determine TNM staging $(n=18)$.

2.2. Covariates. We examined demographic, clinicopathologic, and socioeconomic characteristics of the study population. Patient demographics included age at diagnosis, sex, race/ethnicity (non-Hispanic white, non-Hispanic black, Hispanic, or others), and insurance (private, Medicare only, any Medicaid, or none).

Clinicopathologic features included tumor site, stage at diagnosis, histologic grade (well/moderately differentiated, poorly/undifferentiated), mucinous or signet ring cell histology, and receipt of microsatellite instability (MSI) testing. Tumor site included right colon (cecum, ascending colon, hepatic flexure, and transverse colon), left colon (splenic flexure, descending colon), sigmoid colon, and rectum (rectosigmoid junction, rectum) according to the International Classification of Disease for Oncology, 3rd Edition (ICD-O3). Data on MSI were collected in 2010 only.

Socioeconomic indicators were derived from POC, SEER, and the Area Health Resource File (AHRF). POC contains patient-level data on hospital type (private, government, or nonprofit), an approved residency training program, total bed size, and cancer clinical trial enrollment. We also used a composite census-tract index of socioeconomic status based on measures developed by Yost et al. [25], including occupation, unemployment, poverty, education, income, and housing. The index was constructed to assess the relationship between socioeconomic status and cancer incidence using SEER data, as described elsewhere [26]. Data used in the index were derived from Census 2000 and American Community Survey 2005-2009 and reflect the populations and census tracts covered by the SEER 17 registries. The index (measured in quintiles) was available for study years 2000, 2005, and 2010. In addition, study data were linked with the AHRF, an extensive county-level database of socioeconomic indicators maintained by the U.S. Department of Health and Human Services [27]. We used AHRF data on per capita income, median household income, education level (\% of persons aged $\geq 25$ years with less than a high school diploma, high school or more, or four or more years of college), poverty (\% of persons living below poverty line), unemployment (unemployment rate), total number of active physicians, and total number of gastroenterologists. Cutpoints for all AHRF variables were based on approximate tertiles. Income measures were adjusted to 2010 dollars.

Treatment patterns included type of surgery (partial, subtotal, or total colectomy or proctectomy), number of lymph nodes examined $(0,1-11$, or $\geq 12)$, receipt of chemotherapy, and receipt of radiation therapy (among rectal cancer patients only). As part of POC studies, treatment information was abstracted from medical records and verified by treating physicians. Treating physicians were also asked to provide names and addresses of other physicians who may have treated the patient, who were subsequently contacted for additional treatment details.

2.3. Statistical Analysis. Descriptive statistics (e.g., proportions, means) were used to examine the distribution of covariates by age at diagnosis ( $<50$ years, $50-69$ years, and $\geq 70$ years). Age categories were chosen in an effort to account for the potential heterogeneity of $\mathrm{CRC}$ in older patients (e.g., the CIMP phenotype is most common in female CRC patients aged $\geq 70$ years [28]). Sensitivity analyses that considered different categorizations of age at diagnosis (e.g., $<50$ years, $\geq 50$ years or $<50$ years, $50-64$ years, or $\geq 65$ years) did not appreciably change the results; therefore, we report the results of the primary analysis only. Comparisons between younger and older patients were performed using the Wald chi-square test and based on differences between observed and expected weighted frequencies [29].

To account for potential differences by race/ethnicity, we conducted a stratified analysis of select covariates in the subgroup of younger (age $<50$ years) non-Hispanic white $(n=317)$, non-Hispanic black $(n=200)$, and Hispanic $(n=189)$ patients.

We also examined the proportion of patients who received chemotherapy and radiation therapy by tumor site (colon versus rectum), stage at diagnosis, and age. Patients 
who received therapy or patients for whom it was recommended that they receive therapy but it was unknown whether they did were considered to have received therapy $(n=91)$; patients who refused therapy $(n=221)$ were not considered to have received therapy.

Proportions and means were weighted with stratumspecific sample weights to reflect the population (i.e., SEER) from which the sample was drawn. Sample weights were calculated as the inverse of the sampling proportion for each sampling stratum.

All statistical analyses were conducted using SAS version 9.3 (SAS Institute, Cary, NC). Statistical significance was accepted as $p$ of 0.05 or less. This study was approved by the Institutional Review Board at the University of North Carolina at Chapel Hill (\#15-1957).

\section{Results}

A total of 6,862 stages II and III CRC patients were included in the analysis. Characteristics of the study population by age at diagnosis are shown in Table 1. Younger patients were more likely to be black or Hispanic than patients aged 50-69 and $\geq 70$ years. The majority of younger patients were diagnosed with stage III (versus II) CRC. Tumor site varied considerably with age. In younger patients, $37 \%$ of tumors were located within the rectum and $22 \%$ in the right colon, whereas in patients over the age of 70 years, only $18 \%$ of the tumors were within the rectum, and $48 \%$ were in the right colon. A similar proportion of patients aged 50-69 years had tumors in the rectum and right colon. The proportion of tumors in the left colon was similar across all age groups.

In the analysis of the stratified subset of younger patients by race/ethnicity (Table 2), more whites had private insurance compared to both blacks and Hispanics. There were also differences by tumor site. A larger proportion of young white and Hispanic patients had rectal tumors, whereas tumors in the right colon were most common in young black patients. Although the proportion of tumors classified as high versus low grade was similar by race/ethnicity, a higher proportion of blacks had tumors with mucinous histology compared to whites and Hispanics.

Differences in county-level socioeconomic indicators by age at diagnosis are shown in Table 3 . Fewer young patients lived in areas with lower median household $(<\$ 50,000)$ income compared to the two older groups of patients. A higher proportion of the oldest (age $\geq 70$ years) patients lived in counties with lower $(<10 \%$ living below poverty line) poverty, lower $(<5 \%)$ unemployment rates, and higher education. There was no difference in the total number of physicians or gastroenterologists by age.

The proportion of patients who received chemotherapy differed by age at diagnosis (Table 4). Among stage II colon cancer patients, the proportion of patients who received chemotherapy decreased with increasing age. A larger proportion of stage III colon cancer patients aged $<50$ years and aged 50-69 years received chemotherapy than did patients aged $\geq 70$ years. A similar pattern was observed in stages II and III rectal cancer, with the vast majority of younger patients receiving chemotherapy. The proportion of rectal cancer patients who received radiation therapy decreased with increasing age in both stages II and III. More young patients received MSI testing and had more lymph nodes $(\geq 12)$ examined at surgery (Table 1$)$.

\section{Discussion}

Our results provide a comprehensive assessment of characteristics of young-onset CRC patients across diverse settings and populations. Using a population-based sample, we found important differences in the distribution of young-onset CRC by race/ethnicity. Younger CRC patients were considerably more likely to be black or Hispanic. Moreover, these racial differences were consistent by tumor subsite, histology, and receipt of care.

There were notable racial differences in the subsitespecific distribution of young-onset CRC. Right-sided tumors predominated (39\%) in younger black patients, while young white (41\%) and Hispanic (33\%) patients had a higher proportion of tumors located within the rectum. Young black patients also more frequently had mucinous histology, which is often associated with right-sided colon cancers. Considerable evidence suggests there are distinct CRC subtypes [30-32] and that there may be differences in these subtypes across racial groups. For example, in a recent study of $B R A F$ and KRAS mutations among patients treated with FOLFOX-based chemotherapy in the Alliance N0147 trial [33], KRAS mutation was more common in black patients, while the frequency of $B R A F$ mutation was the highest in tumors from whites. Other studies [34, 35] have found that, among patients with microsatellite-stable or microsatellite-low tumors, blacks have a higher frequency of KRAS mutations compared to whites. This difference was most pronounced in the proximal colon, with no differences in mutation frequency by race in the distal colon or rectum. Combined with the growing evidence on tumor subtypes, the differences in tumor subsite and histology we observed make a compelling argument for distinct mechanisms that drive CRC progression in racial subgroups.

We also observed suboptimal receipt of MSI testing, as well as differences in receipt by race/ethnicity. Treatment guidelines recommend that younger (age < 50) CRC patients undergo MSI testing [36], and more recently, guidelines include the option that all CRC patients, regardless of age, are to be considered for testing [37, 38]. Yet, less than one-third (27\%) of younger patients in our study received MSI testing, and there was substantial missing data $(10 \%$ missing for ages $<50$ years). Fewer young non-Hispanic white (25\%) and Hispanic (24\%) patients received appropriate testing than blacks (32\%), as would be expected given the higher proportion of black patients with MSI-like histology (i.e., mucinous histology; see Table 2). Many of the studies examining the prevalence of Lynch syndrome (testing or results) have been conducted in clinic settings, where use of MSI testing ranges from $71 \%$ in comprehensive cancer centers to $15 \%$ in community hospitals [39, 40]. A different study of the Louisiana Tumor Registry [41] found that only $23 \%$ of young CRC patients received MSI testing. Suboptimal receipt of testing and considerable missing data make it 
TABLE 1: Characteristics of 6,862 patients diagnosed with stages II and III colorectal cancer, 1990-2010, by age at diagnosis.

\begin{tabular}{|c|c|c|c|c|c|c|}
\hline & \multicolumn{2}{|c|}{$\begin{array}{c}\text { Age }<50 \text { years } \\
\quad(n=871)\end{array}$} & \multicolumn{2}{|c|}{$\begin{array}{l}\text { Age } 50-69 \text { years } \\
\quad(n=3,018)\end{array}$} & \multicolumn{2}{|c|}{$\begin{array}{c}\text { Age } \geq 70 \text { years } \\
(n=2,973)\end{array}$} \\
\hline & $n$ & Weighted ${ }^{1} \%$ & $n$ & Weighted ${ }^{1} \%$ & $n$ & Weighted $^{1} \%$ \\
\hline \multicolumn{7}{|l|}{ Demographic characteristics } \\
\hline \multicolumn{7}{|l|}{ Sex $^{*}$} \\
\hline Male & 472 & 54.0 & 1685 & 56.0 & 1377 & 44.3 \\
\hline Female & 399 & 46.0 & 1333 & 44.0 & 1596 & 55.7 \\
\hline \multicolumn{7}{|l|}{ Race/ethnicity* } \\
\hline White, non-Hispanic & 317 & 61.4 & 1490 & 71.5 & 1810 & 81.0 \\
\hline Black, non-Hispanic & 200 & 13.3 & 634 & 11.2 & 449 & 6.7 \\
\hline Hispanic & 189 & 14.7 & 495 & 9.7 & 386 & 6.7 \\
\hline Other & 165 & 10.5 & 399 & 7.6 & 328 & 5.6 \\
\hline \multicolumn{7}{|l|}{ Insurance $^{*}$} \\
\hline Private/HMO/VA/other & 637 & 78.9 & 2214 & 76.8 & 1848 & 67.2 \\
\hline Medicare (only) & 127 & 1.0 & 351 & 9.1 & 685 & 23.0 \\
\hline Medicaid (any) & 13 & 14.4 & 254 & 10.6 & 358 & 9.2 \\
\hline None & 75 & 5.8 & 128 & 3.6 & 21 & 0.6 \\
\hline \multicolumn{7}{|l|}{ Clinicopathologic features } \\
\hline \multicolumn{7}{|l|}{ Tumor site* } \\
\hline Right colon & 176 & 22.4 & 679 & 31.9 & 951 & 46.4 \\
\hline Left colon & 116 & 15.6 & 332 & 15.1 & 379 & 15.4 \\
\hline Sigmoid colon & 137 & 25.1 & 536 & 22.2 & 482 & 20.2 \\
\hline Rectum $^{2}$ & 433 & 36.9 & 1456 & 30.8 & 1140 & 18.0 \\
\hline \multicolumn{7}{|l|}{ Stage at diagnosis ${ }^{*}$} \\
\hline Stage II & 360 & 42.2 & 1437 & 48.7 & 1532 & 54.2 \\
\hline Stage III & 511 & 57.8 & 1581 & 51.3 & 1441 & 45.8 \\
\hline \multicolumn{7}{|l|}{ Histologic grade* } \\
\hline Well/moderately differentiated & 640 & 78.7 & 2352 & 82.2 & 2216 & 73.4 \\
\hline Poorly/undifferentiated & 186 & 21.3 & 526 & 17.8 & 641 & 26.6 \\
\hline Mucinous adenocarcinoma & 110 & 11.1 & 293 & 9.5 & 321 & 11.5 \\
\hline Signet ring cell carcinoma & 12 & 0.8 & 28 & 0.7 & 29 & 1.2 \\
\hline \multicolumn{7}{|l|}{ MSI testing performed ${ }^{3 *}$} \\
\hline Yes & 68 & 27.3 & 83 & 9.7 & 44 & 7.1 \\
\hline No & 140 & 72.7 & 540 & 90.3 & 423 & 92.9 \\
\hline Unknown & 23 & & 29 & & 15 & \\
\hline \multicolumn{7}{|l|}{ Treatment } \\
\hline \multicolumn{7}{|l|}{ Surgery type ${ }^{*}$} \\
\hline Local excision ${ }^{4}$ & 6 & 0.7 & 16 & 0.5 & 16 & 0.4 \\
\hline Partial colectomy or proctectomy ${ }^{5}$ & 480 & 56.4 & 1619 & 50.5 & 1466 & 41.1 \\
\hline Subtotal colectomy & 240 & 30.7 & 839 & 38.4 & 1080 & 50.6 \\
\hline Total colectomy or proctectomy & 98 & 9.1 & 346 & 6.5 & 249 & 3.8 \\
\hline Total proctocolectomy & 38 & 2.4 & 163 & 3.4 & 139 & 3.5 \\
\hline Other & 9 & 0.7 & 35 & 0.7 & 23 & 0.6 \\
\hline \multicolumn{7}{|l|}{ Lymph nodes examined* } \\
\hline 0 & 24 & 1.8 & 89 & 2.0 & 73 & 1.7 \\
\hline $1-11$ & 258 & 25.8 & 1302 & 37.8 & 1499 & 45.0 \\
\hline$\geq 12$ & 560 & 72.4 & 1537 & 60.2 & 1297 & 53.3 \\
\hline
\end{tabular}


TABle 1: Continued.

\begin{tabular}{|c|c|c|c|c|c|c|}
\hline & \multicolumn{2}{|c|}{$\begin{array}{l}\text { Age }<50 \text { years } \\
\quad(n=871)\end{array}$} & \multicolumn{2}{|c|}{$\begin{array}{c}\text { Age } 50-69 \text { years } \\
\quad(n=3,018)\end{array}$} & \multicolumn{2}{|c|}{$\begin{array}{l}\text { Age } \geq 70 \text { years } \\
\quad(n=2,973)\end{array}$} \\
\hline & $n$ & Weighted $^{1} \%$ & $n$ & Weighted $^{1} \%$ & $n$ & Weighted $^{1} \%$ \\
\hline \multicolumn{7}{|c|}{$\begin{array}{l}\text { Socioeconomic indicators } \\
\text { (census-tract-level) }\end{array}$} \\
\hline \multicolumn{7}{|c|}{ SES index ${ }^{6}$} \\
\hline Quintile 1 & 122 & 15.8 & 378 & 18.5 & 322 & 17.2 \\
\hline Quintile 2 & 113 & 21.4 & 350 & 20.3 & 279 & 20.6 \\
\hline Quintile 3 & 109 & 19.5 & 322 & 24.7 & 259 & 17.5 \\
\hline Quintile 4 & 113 & 20.8 & 251 & 16.0 & 276 & 22.2 \\
\hline Quintile 5 & 104 & 22.6 & 275 & 20.6 & 238 & 22.6 \\
\hline \multicolumn{7}{|c|}{ Socioeconomic indicators (patient-level) } \\
\hline \multicolumn{7}{|c|}{ Hospital type* } \\
\hline Private & 67 & 11.9 & 238 & 7.2 & 247 & 10.1 \\
\hline Government & 182 & 16.1 & 540 & 17.4 & 387 & 13.5 \\
\hline Nonprofit & 621 & 72.0 & 2212 & 75.4 & 2313 & 76.4 \\
\hline \multicolumn{7}{|c|}{ Teaching hospital* } \\
\hline No & 370 & 45.2 & 1397 & 51.9 & 1564 & 53.9 \\
\hline Yes & 498 & 54.8 & 1585 & 48.1 & 1374 & 46.1 \\
\hline \multicolumn{7}{|l|}{ Total bed size } \\
\hline$<200$ & 194 & 26.1 & 676 & 25.1 & 710 & 27.2 \\
\hline $200-400$ & 336 & 39.3 & 1330 & 43.2 & 1335 & 43.6 \\
\hline$\geq 400$ & 339 & 34.6 & 982 & 31.6 & 895 & 29.2 \\
\hline \multicolumn{7}{|c|}{ Clinical trial enrollment ${ }^{*}$} \\
\hline No & 728 & 91.7 & 2494 & 94.4 & 2583 & 98.2 \\
\hline Yes & 67 & 8.3 & 179 & 5.6 & 74 & 1.8 \\
\hline
\end{tabular}

* $p<0.05$.

Note. The table does not include patients who did not undergo cancer-directed surgery $(n=167)$ or patients with incomplete staging information $(n=35)$; no variable had more than $10 \%$ missing data; missing observations range from 35 (tumor site) to 737 (clinical trial enrollment).

VA: Veterans Affairs; MSI: microsatellite instability; SES: socioeconomic status.

${ }^{1}$ Proportions weighted by sampling fraction.

${ }^{2}$ The term "rectal" includes both rectum and rectosigmoid junction.

${ }^{3}$ Microsatellite instability collected in 2010 only.

${ }^{4}$ Local excision includes excisional biopsy or polypectomy with or without photodynamic therapy, electrocautery, cryosurgery, laser ablation, laser excision, curette, and fulguration.

${ }^{5}$ Partial proctectomy includes low anterior resection and total mesorectal excision.

${ }^{6}$ Socioeconomic status based on composite census-tract-level indicators from Census 2000 and American Community Survey 2005-2009; limited to data collection years 2000, 2005, and 2010. Louisiana excluded due to Hurricanes Katrina and Rita's impact on populations within Gulf Coast region in 2005.

difficult to draw further conclusions regarding differences in molecular subtypes of CRC by race/ethnicity. Although collection efforts have likely improved since 2010, and SEER now includes site-specific factors on MSI and KRAS mutation, our results highlight continued need for robust sources of molecular data at the population level.

Separately, we found that a higher proportion of younger CRC patients (both stages II and III) received "optimal" treatment, including better nodal counts from surgery, treatment at academic medical centers, enrollment in clinical trials, chemotherapy, and radiation therapy, compared to the two older groups of patients. Even in the setting of stage II colon cancer, where the absolute benefit of chemotherapy is very small, the majority of younger patients (71\%) received adjuvant therapy. This may reflect physician and patient treatment preferences or advances in available therapies [21], including approval of oxaliplatin [42] and capecitabine [43] in the mid-2000s. Many of the younger stage II patients treated with chemotherapy also had high risk features, including T4 tumors (16\% versus $9 \%)$, poorly differentiated histology $(22 \%$ versus $19 \%)$, and inadequately sampled $(<12)$ lymph nodes (33\% versus $28 \%$ ), compared to younger patients who did not receive therapy (data not shown). Despite more aggressive treatment, some research suggests that younger CRC patients have a worse prognosis than older patients of the same stage, or overall survival is similar between the two groups $[4,7,8$, 12-14, 44, 45]. A recent study [46] of colon cancer patients in the National Cancer Data Base found no difference in the relative survival of younger and older patients, even though younger patients more frequently received chemotherapy. Other pooled analyses of data from clinical trials of metastatic CRC showed that younger (age $<50$ years) patients had worse 
TABLE 2: Characteristics of 706 younger (age < 50 years) patients diagnosed with stages II and III colorectal cancer, 1990-2010, by race/ethnicity.

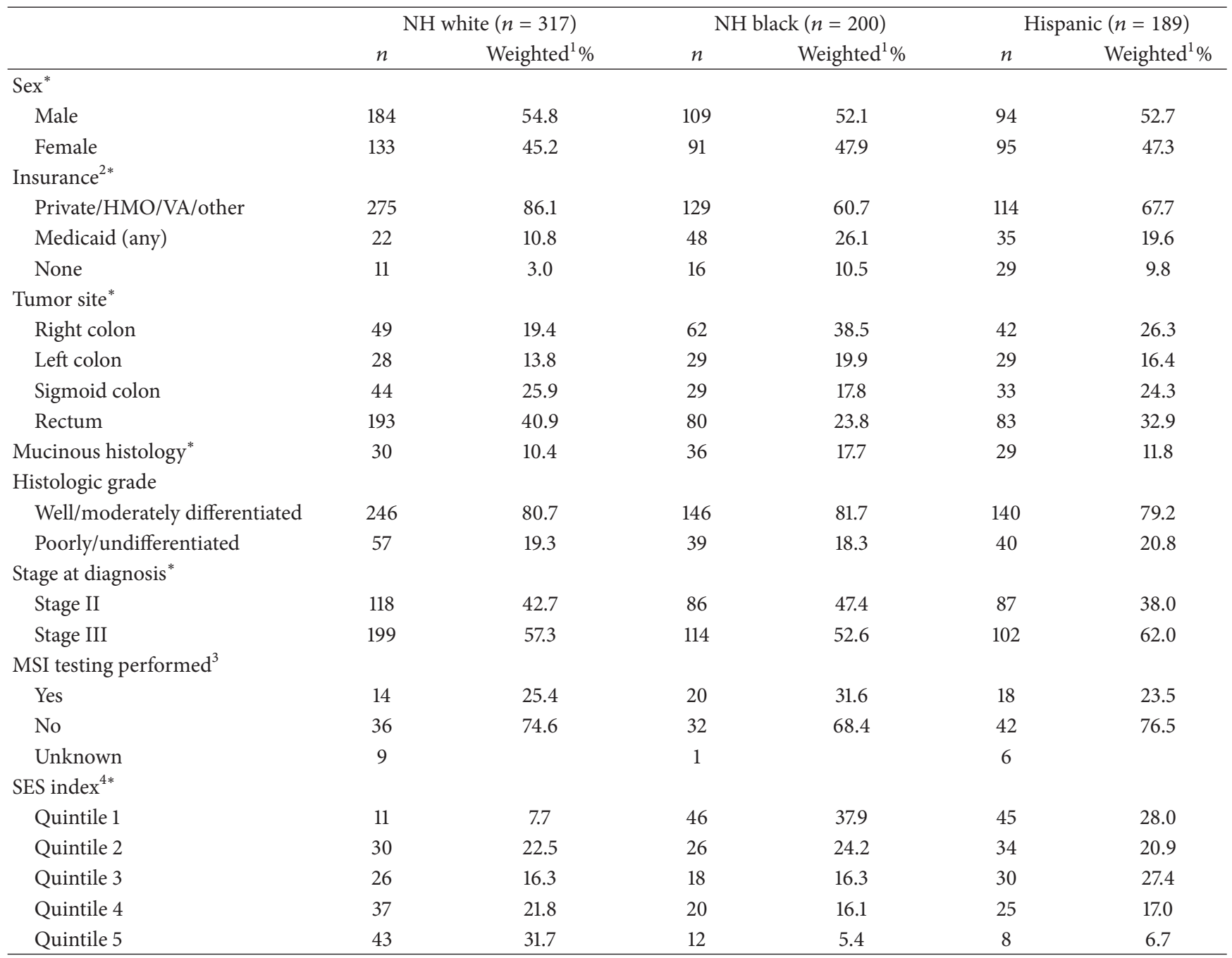

* $p<0.05$.

NH: non-Hispanic; VA: Veterans Affairs; MSI: microsatellite instability; SES: socioeconomic status.

${ }^{1}$ Proportions weighted by sampling fraction.

${ }^{2}$ Percentages do not add to 100 because some younger patients were insured through Medicare; cell sizes too small $(<5)$ to report.

${ }^{3}$ MSI testing collected in 2010 only.

${ }^{4}$ Socioeconomic status based on composite census-tract-level indicators from Census 2000 and American Community Survey 2005-2009; limited to study years 2000, 2005, and 2010 and not including Louisiana.

progression-free and overall survival compared to patients of middle age (approximately aged 57 years), despite equivalent cancer stage and treatment [47].

An important strength of our study is the populationbased sample. Data from POC studies offer a number of unique advantages for conducting population-based epidemiologic research because each participating registry area has a defined population. The age and sex distributions of patients in POC reflect those of the US population, and the SEER program includes registries with a high percentage of African Americans (Detroit, Atlanta, and Louisiana) and Hispanics (Los Angeles, Greater California, and New Mexico). POC data also provide a greater breadth and depth of information than that available solely from medical claims and/or SEER registries; detailed tumor and treatment information is abstracted from patient medical records and verified by treating physicians. This was particularly true for our assessment of receipt of chemotherapy and radiation therapy, where doctor verification substantially improved the completeness of treatment ascertainment.

The large size and diversity of this study population were also strengths that enabled us to examine CRC characteristics within population subgroups by race/ethnicity. We found that a higher proportion of Hispanic patients were diagnosed at younger ages than whites. Due to a variety of concerns, including misclassification and cultural or other differences among Hispanic and Latino groups, there has historically been limited information on cancer trends in Hispanic populations [48]. Hispanics represent the fastestgrowing and youngest minority group in the US [49], and 
TABLE 3: County-level socioeconomic indicators of 6,862 patients diagnosed with stages II and III colorectal cancer, 1990-2010, by age at diagnosis.

\begin{tabular}{|c|c|c|c|c|c|c|}
\hline & \multicolumn{2}{|c|}{$\begin{array}{c}\text { Age }<50 \text { years } \\
\quad(n=871)\end{array}$} & \multicolumn{2}{|c|}{$\begin{array}{c}\text { Age } 50-69 \text { years } \\
\quad(n=3,018)\end{array}$} & \multicolumn{2}{|c|}{$\begin{array}{c}\text { Age } \geq 70 \text { years } \\
\quad(n=2,973)\end{array}$} \\
\hline & $n$ & Weighted ${ }^{1} \%$ & $n$ & Weighted $\%$ & $n$ & Weighted $^{1} \%$ \\
\hline \multicolumn{7}{|l|}{ Per capita income $e^{2 *}$} \\
\hline$<\$ 32,000$ & 133 & 15.4 & 665 & 23.2 & 718 & 24.8 \\
\hline$\$ 32,000-50,000$ & 575 & 66.0 & 1909 & 62.8 & 1818 & 58.1 \\
\hline$>\$ 50,000$ & 163 & 18.6 & 444 & 14.0 & 437 & 17.1 \\
\hline Median & \multicolumn{2}{|c|}{39637} & \multicolumn{2}{|c|}{38380} & \multicolumn{2}{|c|}{38337} \\
\hline \multicolumn{7}{|c|}{ Median household income ${ }^{2}$} \\
\hline$<\$ 50,000$ & 176 & 18.8 & 736 & 24.2 & 691 & 22.8 \\
\hline$\$ 50,000-75,000$ & 558 & 67.6 & 1870 & 63.1 & 1838 & 61.9 \\
\hline$>\$ 75,000$ & 137 & 13.6 & 412 & 12.7 & 444 & 15.3 \\
\hline Median & \multicolumn{2}{|c|}{57755} & \multicolumn{2}{|c|}{56931} & \multicolumn{2}{|c|}{57745} \\
\hline \multicolumn{7}{|l|}{$\%$ living in poverty ${ }^{3 *}$} \\
\hline$<10$ & 214 & 32.6 & 619 & 30.0 & 626 & 36.5 \\
\hline $10-19$ & 409 & 55.5 & 1165 & 54.4 & 1037 & 52.9 \\
\hline$\geq 20$ & 99 & 11.9 & 387 & 15.6 & 299 & 10.7 \\
\hline Median & \multicolumn{2}{|c|}{12.8} & \multicolumn{2}{|c|}{12.7} & \multicolumn{2}{|c|}{11.9} \\
\hline \multicolumn{7}{|c|}{ \% less than high school ${ }^{*}$} \\
\hline$<10$ & 378 & 37.3 & 1471 & 43.3 & 1614 & 48.7 \\
\hline $10-19$ & 377 & 45.9 & 1155 & 39.8 & 1042 & 36.4 \\
\hline$\geq 20$ & 116 & 16.8 & 392 & 16.9 & 317 & 14.8 \\
\hline Median & \multicolumn{2}{|c|}{12.1} & \multicolumn{2}{|c|}{11.4} & \multicolumn{2}{|c|}{10.2} \\
\hline \multicolumn{7}{|c|}{ Unemployment rate $(\%)^{*}$} \\
\hline$<5$ & 273 & 30.6 & 976 & 32.6 & 1090 & 36.5 \\
\hline $5-9$ & 437 & 45.7 & 1550 & 43.1 & 1499 & 45.2 \\
\hline$\geq 10$ & 161 & 23.7 & 492 & 24.3 & 384 & 18.3 \\
\hline Median & \multicolumn{2}{|c|}{5.8} & \multicolumn{2}{|c|}{5.7} & \multicolumn{2}{|c|}{5.3} \\
\hline \multicolumn{7}{|c|}{ Total physicians per 100,000} \\
\hline$<200$ & 209 & 26.7 & 793 & 30.6 & 801 & 28.4 \\
\hline $200-400$ & 473 & 52.3 & 1560 & 48.4 & 1440 & 48.6 \\
\hline$\geq 400$ & 189 & 21.0 & 665 & 21.0 & 732 & 23.0 \\
\hline Median & \multicolumn{2}{|c|}{268.2} & \multicolumn{2}{|c|}{268.3} & \multicolumn{2}{|c|}{268.4} \\
\hline $\begin{array}{l}\text { Total gastroenterol } \\
100,000^{3}\end{array}$ & & & & & & \\
\hline$<3$ & 201 & 30.3 & 625 & 32.0 & 581 & 32.0 \\
\hline $3-5$ & 310 & 41.7 & 957 & 42.6 & 845 & 38.1 \\
\hline$>5$ & 211 & 28.0 & 589 & 25.5 & 536 & 29.9 \\
\hline Median & & & & & & \\
\hline
\end{tabular}

${ }^{*} p<0.05$.

Note. Cutpoints based on approximate tertiles.

${ }^{1}$ Proportions weighted by sampling fraction.

${ }^{2}$ Adjusted to 2010 dollars.

${ }^{3}$ Poverty and total number of gastroenterologists not collected in 1990/91.

their inclusion in cancer statistics has become increasingly relevant. More recent efforts to describe cancer incidence in diverse populations show that the overall incidence rates of CRC are lower in Hispanics than in non-Hispanic whites [50], although there may be some differences in incidence by country of origin (e.g., higher incidence rates are observed in Cuban Americans) [51].

Our study population was limited to stages II and III patients. There may be different characteristics of younger CRC patients when considering early-stage or metastatic 
TABLE 4: Receipt of chemotherapy and radiation therapy among 6,862 patients diagnosed with stages II and III colorectal cancer, 1990-2010, by age and stage at diagnosis.

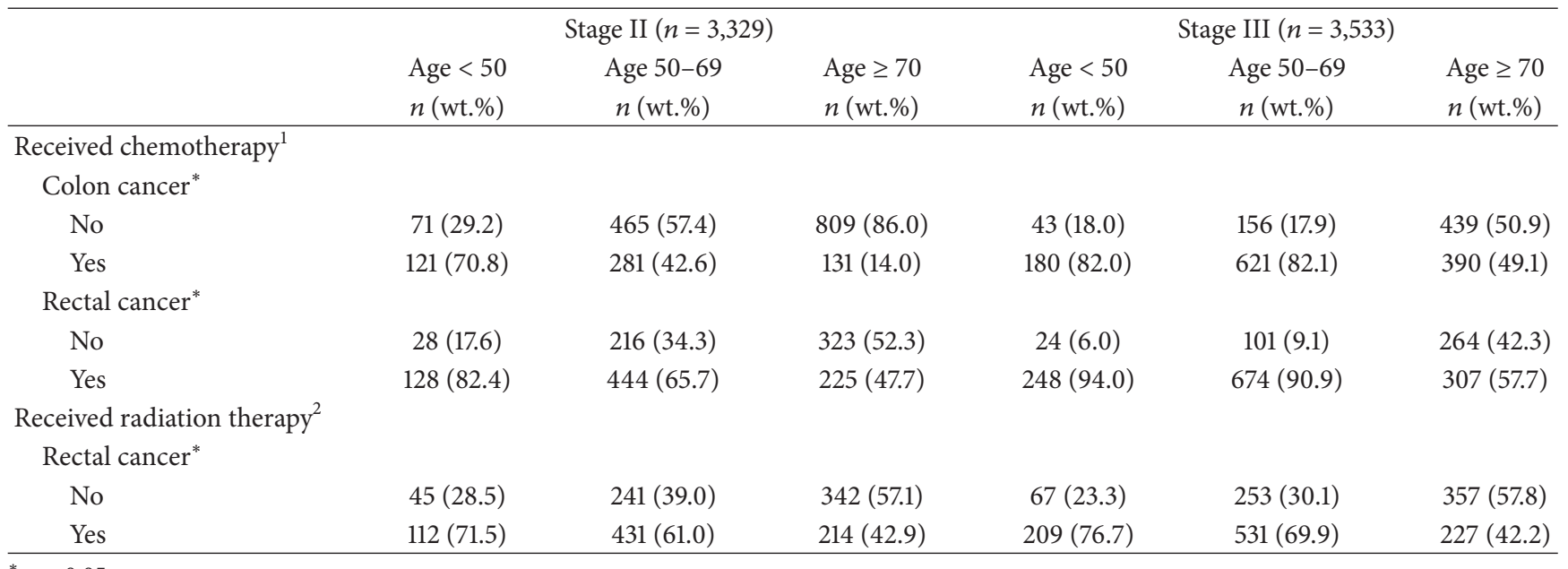

* $p<0.05$.

Note. Proportions weighted by sampling fraction.

wt.: weighted.

${ }^{1}$ Receipt of chemotherapy includes both neoadjuvant and adjuvant (or both) chemotherapy.

${ }^{2}$ Receipt of radiation therapy includes postoperative and preoperative radiation.

disease. For example, we observed only slight differences in county-level socioeconomic indicators among younger and older patients, but a relationship between CRC and socioeconomic status has been demonstrated most consistently in late-stage disease [52-55]. The increase in the number of younger patients diagnosed with stages II and III CRC in our study may also be a reflection of stage migration (i.e., some cases once considered stage I would now be classified as stage II); however, evidence has consistently shown meaningful increases in all stages of young-onset CRC [3]. In addition, we did not have information on genetic predisposition to CRC, either by hereditary syndrome or by a first-degree relative with a history of CRC. These data may have helped explain changes in the distribution of young-onset CRC over time, but the prevalence of hereditary syndromes in younger populations remains very low [56].

In summary, our study provides compelling evidence that characteristics of patients diagnosed with young-onset CRC differ considerably by race/ethnicity. These differences may reflect racial differences in CRC risk factors rather than disparities in diagnosis and treatment. Although exact mechanisms remain unknown, higher incidence of CRC among young black and Hispanic populations may be due to differential exposure to lifestyle-related risk factors, such as dietary patterns and a higher prevalence of obesity and sedentary behavior. Understanding differences in these risk factors by age and race/ethnicity may better elucidate reasons for the recent increase in CRC incidence in younger populations.

\section{Disclosure}

Dr. Sanoff received research funding through Bayer and Novartis and Dr. Lund received a Research Starter Award from the Pharmaceutical Research and Manufacturers of America (PhRMA) Foundation.

\section{Competing Interests}

The authors declare that they have no competing interests regarding the publication of this paper.

\section{Acknowledgments}

This study was supported by the National Institutes of Health Grants T32DK07643, K07CA160772 (Hanna K. Sanoff), and K12CA120780 (Jennifer L. Lund).

\section{References}

[1] R. L. Siegel, A. Jemal, and E. M. Ward, "Increase in incidence of colorectal cancer among young men and women in the United States," Cancer Epidemiology Biomarkers and Prevention, vol. 18, no. 6, pp. 1695-1698, 2009.

[2] T. L. Fairley, C. J. Cardinez, J. Martin et al., "Colorectal cancer in U.S. adults younger than 50 years of age, 1998-2001," Cancer, vol. 107, S5, pp. 1153-1161, 2006.

[3] C. E. Bailey, C.-Y. Hu, Y. N. You et al., "Increasing disparities in the age-related incidences of colon and rectal cancers in the United States, 1975-2010," JAMA Surgery, vol. 150, no. 1, pp. 1722, 2015.

[4] B. Karsten, J. Kim, J. King, and R. R. Kumar, "Characteristics of colorectal cancer in young patients at an urban county hospital," American Surgeon, vol. 74, no. 10, pp. 973-976, 2008.

[5] K. Marble, S. Banerjee, and L. Greenwald, "Colorectal carcinoma in young patients," Journal of Surgical Oncology, vol. 51, no. 3, pp. 179-182, 1992.

[6] N. Savas, U. Dagli, S. Akbulut, O. Yuksel, and B. Sahin, "Colorectal cancer localization in young patients: should we expand the screening program?" Digestive Diseases and Sciences, vol. 52, no. 3, pp. 798-802, 2007.

[7] E. Mitry, A.-M. Benhamiche, J.-L. Jouve, F. Clinard, C. FinnFaivre, and J. Faivre, "Colorectal adenocarcinoma in patients 
under 45 years of age: comparison with older patients in a welldefined French population," Diseases of the Colon and Rectum, vol. 44, no. 3, pp. 380-387, 2001.

[8] J. Brant Parramore, J. P. Wei, and K. A. Yeh, "Colorectal cancer in patients under forty: presentation and outcome," American Surgeon, vol. 64, no. 6, pp. 563-568, 1998.

[9] V. S. Schellerer, S. Merkel, S. C. Schumann et al., "Despite aggressive histopathology survival is not impaired in young patients with colorectal cancer: CRC in patients under 50 years of age," International Journal of Colorectal Disease, vol. 27, no. 1, pp. 71-79, 2012.

[10] R. K. Yantiss, M. Goodarzi, X. K. Zhou et al., "Clinical, pathologic, and molecular features of early-onset colorectal carcinoma," American Journal of Surgical Pathology, vol. 33, no. 4, pp. 572-582, 2009.

[11] J.-M. Chiang, M.-C. Chen, C. R. Changchien et al., "Favorable influence of age on tumor characteristics of sporadic colorectal adenocarcinoma: patients 30 years of age or younger may be a distinct patient group," Diseases of the Colon and Rectum, vol. 46, no. 7, pp. 904-910, 2003.

[12] C.-L. Chou, S.-C. Chang, T.-C. Lin et al., "Differences in clinicopathological characteristics of colorectal cancer between younger and elderly patients: an analysis of 322 patients from a single institution," American Journal of Surgery, vol. 202, no. 5, pp. 574-582, 2011.

[13] S. Ganapathi, D. Kumar, N. Katsoulas et al., "Colorectal cancer in the young: trends, characteristics and outcome," International Journal of Colorectal Disease, vol. 26, no. 7, pp. 927-934, 2011.

[14] P. M. Griffin, J. M. Liff, R. S. Greenberg, and W. S. Clark, "Adenocarcinomas of the colon and rectum in persons under 40 years old. A population-based study," Gastroenterology, vol. 100, no. 4, pp. 1033-1040, 1991.

[15] M. Li, J.-Y. Li, A.-L. Zhao, and J. Gu, "Do young patients with colorectal cancer have a poorer prognosis than old patients?" Journal of Surgical Research, vol. 167, no. 2, pp. 231-236, 2011.

[16] J. T. Liang, K. C. Huang, A. L. Cheng, Y. M. Jeng, M. S. Wu, and S. M. Wang, "Clinicopathological and molecular biological features of colorectal cancer in patients less than 40 years of age," British Journal of Surgery, vol. 90, no. 2, pp. 205-214, 2003.

[17] L. C. Harlan, L. X. Clegg, J. Abrams, J. L. Stevens, and R. Ballard-Barbash, "Community-based use of chemotherapy and hormonal therapy for early-stage breast cancer: 1987-2000," Journal of Clinical Oncology, vol. 24, no. 6, pp. 872-877, 2006.

[18] L. C. Harlan, C. N. Klabunde, A. H. Ambs et al., "Comorbidities, therapy, and newly diagnosed conditions for women with early stage breast cancer," Journal of Cancer Survivorship, vol. 3, no. 2, pp. 89-98, 2009.

[19] J. A. Zujewski, L. C. Harlan, D. M. Morrell, and J. L. Stevens, "Ductal carcinoma in situ: trends in treatment over time in the US," Breast Cancer Research and Treatment, vol. 127, no. 1, pp. 251-257, 2011.

[20] D. P. Cronin, L. C. Harlan, A. L. Potosky, L. X. Clegg, J. L. Stevens, and M. M. Mooney, "Patterns of care for adjuvant therapy in a random population-based sample of patients diagnosed with colorectal cancer," American Journal of Gastroenterology, vol. 101, no. 10, pp. 2308-2318, 2006.

[21] C. C. Murphy, L. C. Harlan, J. L. Lund, C. F. Lynch, and A. M. Geiger, "Patterns of colorectal cancer care in the United States: 1990-2010," Journal of the National Cancer Institute, vol. 107, no. 10, Article ID djv198, 2015.

[22] C. C. Murphy, L. C. Harlan, J. L. Warren, and A. M. Geiger, "Race and insurance differences in the receipt of adjuvant chemotherapy among patients with stage III colon cancer," Journal of Clinical Oncology, vol. 33, no. 23, pp. 2530-2536, 2015.

[23] A. L. Potosky, L. C. Harlan, R. S. Kaplan, K. A. Johnson, and C. F. Lynch, "Age, sex, and racial differences in the use of standard adjuvant therapy for colorectal cancer," Journal of Clinical Oncology, vol. 20, no. 5, pp. 1192-1202, 2002.

[24] E. L. Trimble, L. C. Harlan, D. Gius, J. Stevens, and S. M. Schwartz, "Patterns of care for women with cervical cancer in the United States," Cancer, vol. 113, no. 4, pp. 743-749, 2008.

[25] K. Yost, C. Perkins, R. Cohen, C. Morris, and W. Wright, "Socioeconomic status and breast cancer incidence in California for different race/ethnic groups," Cancer Causes and Control, vol. 12, no. 8, pp. 703-711, 2001.

[26] M. Yu, Z. Tatalovich, J. T. Gibson, and K. A. Cronin, "Using a composite index of socioeconomic status to investigate health disparities while protecting the confidentiality of cancer registry data," Cancer Causes and Control, vol. 25, no. 1, pp. 81-92, 2014.

[27] U.S. Department of Health and Human Services, Health Resources and Services Administration, and Bureau of Health Professions, Area Health Resource File (AHRF), http://ahrf.hrsa.gov/.

[28] D. J. Weisenberger, A. J. Levine, T. I. Long et al., "Association of the colorectal CpG island methylator phenotype with molecular features, risk factors, and family history," Cancer Epidemiology Biomarkers and Prevention, vol. 24, no. 3, pp. 512-519, 2015.

[29] M. E. Stokes, C. S. Davis, and G. G. Koch, Categorical Data Analysis Using SAS , SAS Institute, 2012.

[30] F. A. Sinicrope, Q. Shi, T. C. Smyrk et al., "Molecular markers identify subtypes of stage III colon cancer associated with patient outcomes," Gastroenterology, vol. 148, no. 1, pp. 88-99, 2015.

[31] The Cancer Genome Atlas Network, "Comprehensive molecular characterization of human colon and rectal cancer," Nature, vol. 487, no. 7407, pp. 330-337, 2012.

[32] J. Guinney, R. Dienstmann, X. Wang et al., "The consensus molecular subtypes of colorectal cancer," Nature Medicine, vol. 21, no. 11, pp. 1350-1356, 2015.

[33] H. H. Yoon, Q. Shi, S. R. Alberts et al., "Racial differences in BRAF/KRAS mutation rates and survival in stage III colon cancer patients," Journal of the National Cancer Institute, vol. 107, no. 10, 2015.

[34] K. Kumar, H. Brim, F. Giardiello et al., "Distinct BRAF (V600E) and KRAS mutations in high microsatellite Instability sporadic colorectal cancer in African Americans," Clinical Cancer Research, vol. 15, no. 4, pp. 1155-1161, 2009.

[35] B. E. Sylvester, D. Huo, A. Khramtsov et al., "Molecular analysis of colorectal tumors within a diverse patient cohort at a single institution," Clinical Cancer Research, vol. 18, no. 2, pp. 350-359, 2012.

[36] A. Umar, C. R. Boland, J. P. Terdiman et al., "Revised Bethesda Guidelines for hereditary nonpolyposis colorectal cancer (Lynch syndrome) and microsatellite instability," Journal of the National Cancer Institute, vol. 96, no. 4, pp. 261-268, 2004.

[37] A. B. Benson III, T. Bekaii-Saab, E. Chan et al., "Rectal cancer," JNCCN Journal of the National Comprehensive Cancer Network, vol. 10, no. 12, pp. 1528-1564, 2012.

[38] A. B. Benson, A. P. Venook, T. Bekaii-Saab et al., "Colon cancer, version 3.2014," Journal of the National Comprehensive Cancer Network, vol. 12, no. 7, pp. 1028-1059, 2014.

[39] L. C. Beamer, M. L. Grant, C. R. Espenschied et al., "Reflex immunohistochemistry and microsatellite instability testing 
of colorectal tumors for lynch syndrome among US cancer programs and follow-up of abnormal results," Journal of Clinical Oncology, vol. 30, no. 10, pp. 1058-1063, 2012.

[40] K. Kessels, H. H. Fidder, N. L. De Groot et al., "Adherence to microsatellite instability testing in young-onset colorectal cancer patients," Diseases of the Colon and Rectum, vol. 56, no. 7, pp. 825-833, 2013.

[41] J. J. Karlitz, M.-C. Hsieh, Y. Liu et al., "Population-based lynch syndrome screening by microsatellite instability in patients $\leq 50$ : prevalence, testing determinants, and result availability prior to colon surgery," American Journal of Gastroenterology, vol. 110, no. 7, pp. 948-955, 2015.

[42] T. André, C. Boni, L. Mounedji-Boudiaf et al., "Oxaliplatin, fluorouracil, and leucovorin as adjuvant treatment for colon cancer," New England Journal of Medicine, vol. 350, no. 23, pp. 2343-2351, 2004.

[43] C. Twelves, A. Wong, M. P. Nowacki et al., "Capecitabine as adjuvant treatment for stage III colon cancer," The New England Journal of Medicine, vol. 352, no. 26, pp. 2696-2704, 2005.

[44] F. Paraf and S. Jothy, "Colorectal cancer before the age of 40: a case-control study," Diseases of the Colon and Rectum, vol. 43, no. 9, pp. 1222-1226, 2000.

[45] H. M. Quah, R. Joseph, D. Schrag et al., "Young age influences treatment but not outcome of colon cancer," Annals of Surgical Oncology, vol. 14, no. 10, pp. 2759-2765, 2007.

[46] P. J. Kneuertz, G. J. Chang, C.-Y. Hu et al., "Overtreatment of young adults with colon cancer: more intense treatments with unmatched survival gains," JAMA Surgery, vol. 150, no. 5, pp. 402-409, 2015.

[47] C. H. Lieu, L. A. Renfro, A. De Gramont et al., "Association of age with survival in patients with metastatic colorectal cancer: analysis from the ARCAD clinical trials program," Journal of Clinical Oncology, vol. 32, no. 27, pp. 2975-2982, 2014.

[48] H. L. Howe, X. Wu, L. A. G. Ries et al., "Annual report to the nation on the status of cancer, 1975-2003, featuring cancer among U.S. Hispanic/Latino populations," Cancer, vol. 107, no. 8, pp. 1711-1742, 2006.

[49] S. R. Ennis, M. Ríos-Vargas, and N. G. Albert, Census USBot: The Hispanic Population: 2010: US Department of Commerce, Economics and Statistics Administration, US Census Bureau, 2011.

[50] American Cancer Society, Cancer Facts \& Figures for Hispanics, American Cancer Society, Atlanta, Ga, USA, 2009.

[51] P. S. Pinheiro, R. L. Sherman, E. J. Trapido et al., "Cancer incidence in first generation U.S. Hispanics: Cubans, Mexicans, Puerto Ricans, and New Latinos," Cancer Epidemiology Biomarkers and Prevention, vol. 18, no. 8, pp. 2162-2169, 2009.

[52] R. L. Siegel, A. Jemal, M. J. Thun, Y. Hao, and E. M. Ward, "Trends in the incidence of colorectal cancer in relation to county-level poverty among blacks and whites," Journal of the National Medical Association, vol. 100, no. 12, pp. 1441-1444, 2008.

[53] E. Ward, A. Jemal, V. Cokkinides et al., "Cancer disparities by race/ethnicity and socioeconomic status," Ca-A Cancer Journal for Clinicians, vol. 54, no. 2, pp. 78-93, 2004.

[54] C. A. Doubeni, T. S. Field, D. S. M. Buist et al., "Racial differences in tumor stage and survival for colorectal cancer in an insured population," Cancer, vol. 109, no. 3, pp. 612-620, 2007.

[55] X. L. Du, S. Fang, S. W. Vernon et al., "Racial disparities and socioeconomic status in association with survival in a large population-based cohort of elderly patients with colon cancer," Cancer, vol. 110, no. 3, pp. 660-669, 2007.
[56] P. J. Limburg, W. S. Harmsen, H. H. Chen et al., "revalence of alterations in DNA mismatch repair genes in patients with young-onset colorectal cancer," Clinical Gastroenterology and Hepatology, vol. 9, no. 6, pp. 497-502, 2011. 


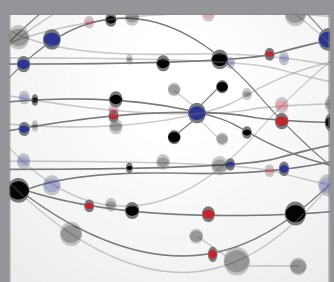

The Scientific World Journal
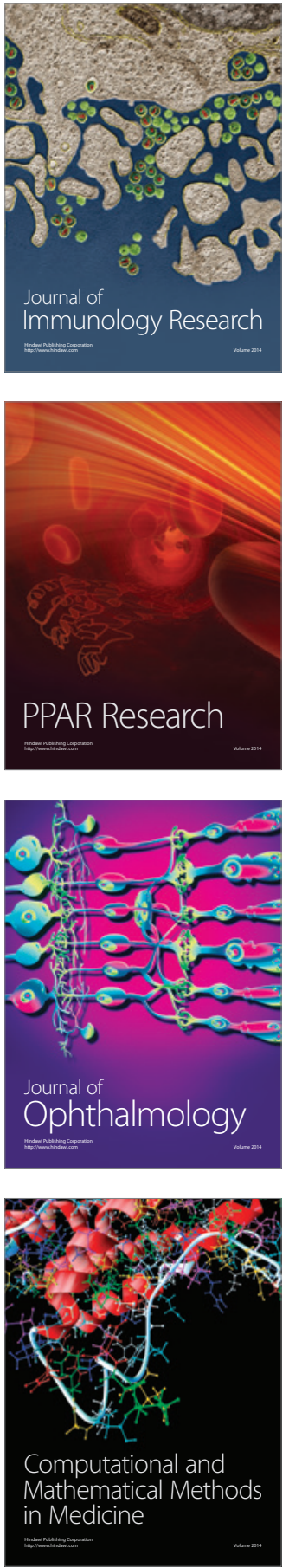

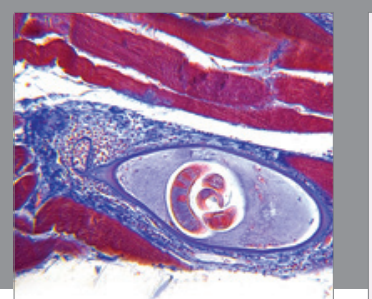

Gastroenterology Research and Practice
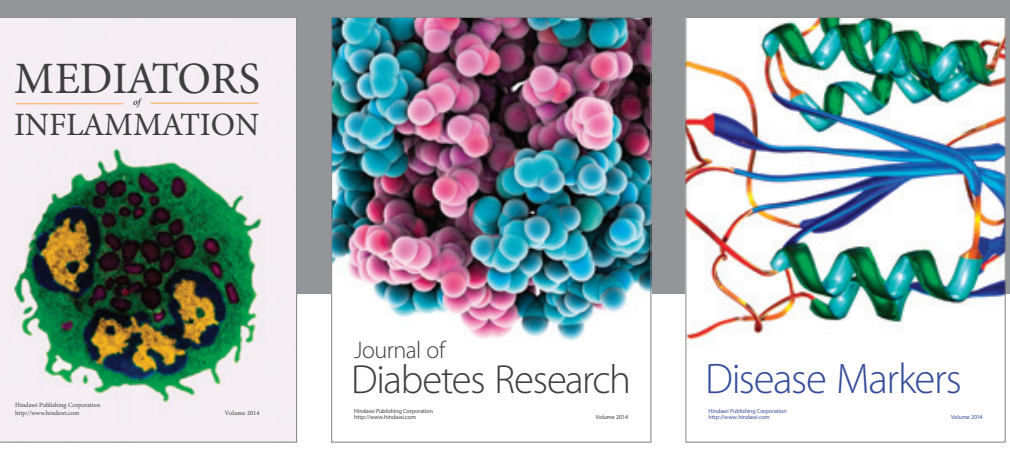

Disease Markers

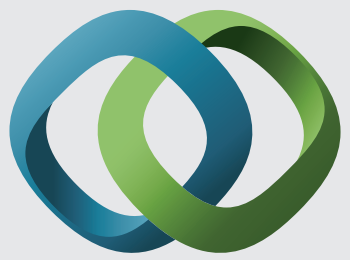

\section{Hindawi}

Submit your manuscripts at

https://www.hindawi.com
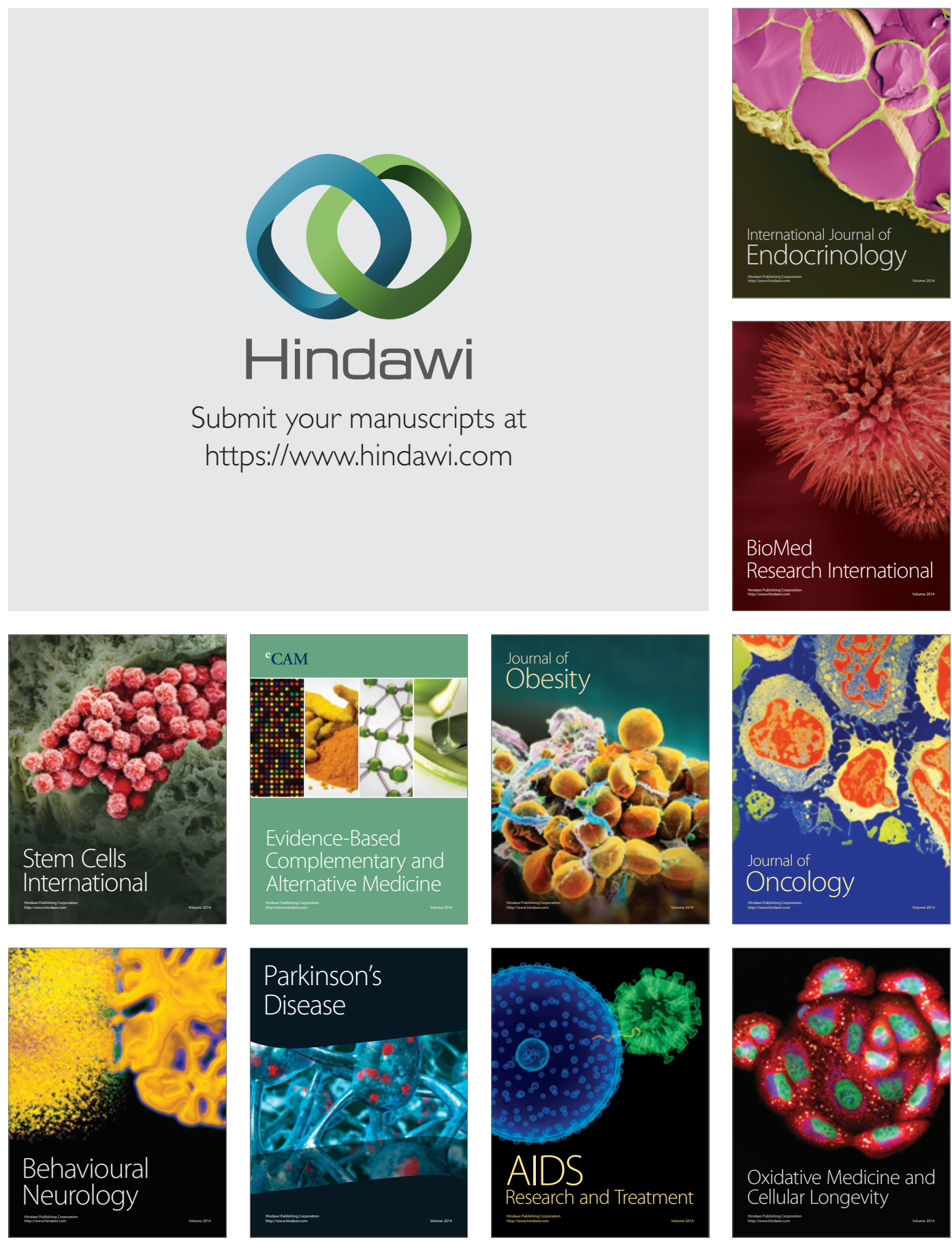